\title{
Influence of certain process parameters on the morphology of CVD-synthesized multiwalled carbon nanotubes at reduced pressure
}

\author{
A. N. Kovalenko ${ }^{1}$, X. Devaux ${ }^{2}$, S. Yu. Tsareva ${ }^{1 *}$, L.D. Iskhakova ${ }^{3}$, \\ E. V. Zharikov ${ }^{1}$, E. McRae ${ }^{4}$ \\ ${ }^{1}$ D. Mendeleev University of Chemical Technology of Russia, 9, Miusskaya sq., Moscow, \\ 125047, Russia \\ ${ }^{2}$ Laboratoire de Physique des Matériaux UMR 7556, Nancy Université, CNRS, Ecole des \\ Mines, 54042 Nancy, France \\ ${ }^{3}$ Fiber Optics Research Center of the Russian Academy of Sciences, 38, Vavilov Street, \\ Moscow, 119991, Russia \\ ${ }^{4}$ Laboratoire de Chimie du Solide Minéral UMR 7555, Nancy Université, CNRS, B.P. 239, \\ 54506 Vandoeuvre, France \\ *tsarjova@rctu.ru
}

Over the past fifteen years, an enormous number of scientific publications and several books [1-4] have examined the synthesis, characterization, theory and potential applications of carbon nanotubes. These materials have a combination of many outstanding properties but one of the major hindrances to their real-world applications is the lack of controlled synthesis so as to produce a given type of carbon nanotube from among the huge variety of carbon nanostructures, the synthesis conditions of which often differ little from one type of nanostructure to another.

In this work, we present some results pertaining to the CVD synthesis [3, 4] of multiwalled carbon nanotubes (CNTs) under reduced pressure. The schematic drawing of the reactor utilized is given in figure 1 .

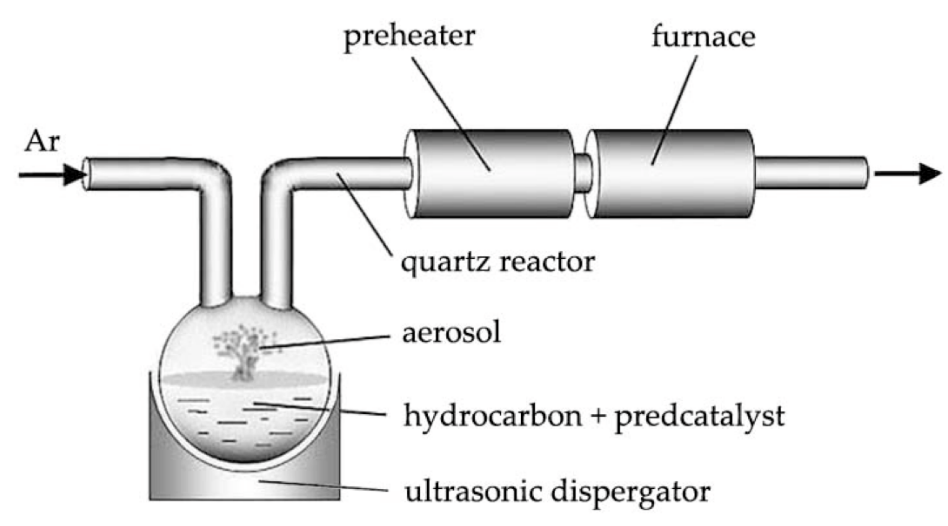

Fig. 1. Schematic representation of the synthesis reactor. Under the conditions used for this work, the hydrocarbon and precatalysts were benzene and ferrocene respectively.

A solution of benzene with ferrocene $\left[\mathrm{Fe}\left(\mathrm{C}_{5} \mathrm{H}_{5}\right)_{2}\right]$ as precatalyst; was prepared. The aerosol was generated by ultrasonic vibration of this hydrocarbon - precatalyst mixture. We used an ultrasonic frequency of $2.64 \mathrm{MHz}$ which produces a droplet size of $1.5-2 \mu \mathrm{m}$. Argon was utilized as the inert gas to take the hydrocarbon and precatalyst into the furnace. Since ferrocene is only slightly soluble in benzene, an additional quantity of ferrocene was introduced by evaporation in a preheater. Sulphur was added to the process in the form of $\mathrm{CS}_{2}$ dissolved in benzene. We used ferrocene as a precatalyst because its temperature of 
decomposition is close to that of benzene in $\mathrm{Ar}$ atmosphere (near $500^{\circ} \mathrm{C}$ ). Furthermore, upon decomposition, ferrocene gives pure iron particles. The pressure in the reactor was about 0.85 atm. A reduced pressure allowed decreasing the temperature of decomposition of both benzene and ferrocene and thereby diminishing the melting temperature of the catalyst particles. Table 1 shows the synthesis conditions for the four samples examined here. We could control the temperature of the process in the centre of the furnace, the argon flow rate and the catalyst concentration.

\begin{tabular}{|c|c|c|c|}
\hline Sample & $\mathbf{T},{ }^{\circ} \mathbf{C}$ & $\mathbf{V}(\mathbf{A r}), \mathbf{m l} / \mathbf{h}$ & $\mathbf{F e}, \mathbf{a t} \%$ \\
\hline 1 & 800 & 6000 & 5 \\
\hline 2 & 950 & 6000 & 5 \\
\hline 3 & 950 & 6000 & 2 \\
\hline 4 & 950 & 1200 & 2 \\
\hline
\end{tabular}

Table 1. Synthesis conditions for the four samples examined in this work: furnace temperature, argon flow rate and catalyst concentration. We have added into the solution of benzene and ferrocene $1.3 \mathrm{wt} \%$ of $\mathrm{CS}_{2}$

The different samples were extensively studied by both transmission (TEM, Philips CM200) and scanning electron microscopy (SEM, FEI Quanta-FEG-600 and Philips XL30 FEG). After sonication in ethanol, all samples were deposited on an amorphous carbon-coated copper grid.

Let us now examine the results. Figure 2 shows representative TEM micrographs of the sample obtained at the lower of the temperatures used $\left(800^{\circ} \mathrm{C}\right)$. We observed mostly thick tubes $\left(d_{\text {ext }}=200-300 \mathrm{~nm}\right)$ with internal diameters $d_{\text {int }}=15-40 \mathrm{~nm}$. A small number of tubes can be observed with $d_{\text {ext }}=500$ to $700 \mathrm{~nm}$ and also thinner tubes with $d_{\text {ext }}$ less than $100 \mathrm{~nm}$. As can be seen on fig. 2, 200 to $300 \mathrm{~nm}$ spheres are often located on the surfaces of the thick tubes and metallic particles (often not spherical) at their extremities. The HRTEM micrograph shows the walls of a thick MWNT. It can be observed that the lattice planes are quite parallel and well organized. The ordering of the graphene planes decreases from the inner channel to the external part of the tube. At the surface one can see an amorphous layer of carbon.

This tube structure is typical of all of the thick tubes that have been studied in our samples. The spheres observed are composed of a few nanoparticles of iron surrounded by carbon. A high concentration of sulphur was also detected in these nanoparticles by EDS.
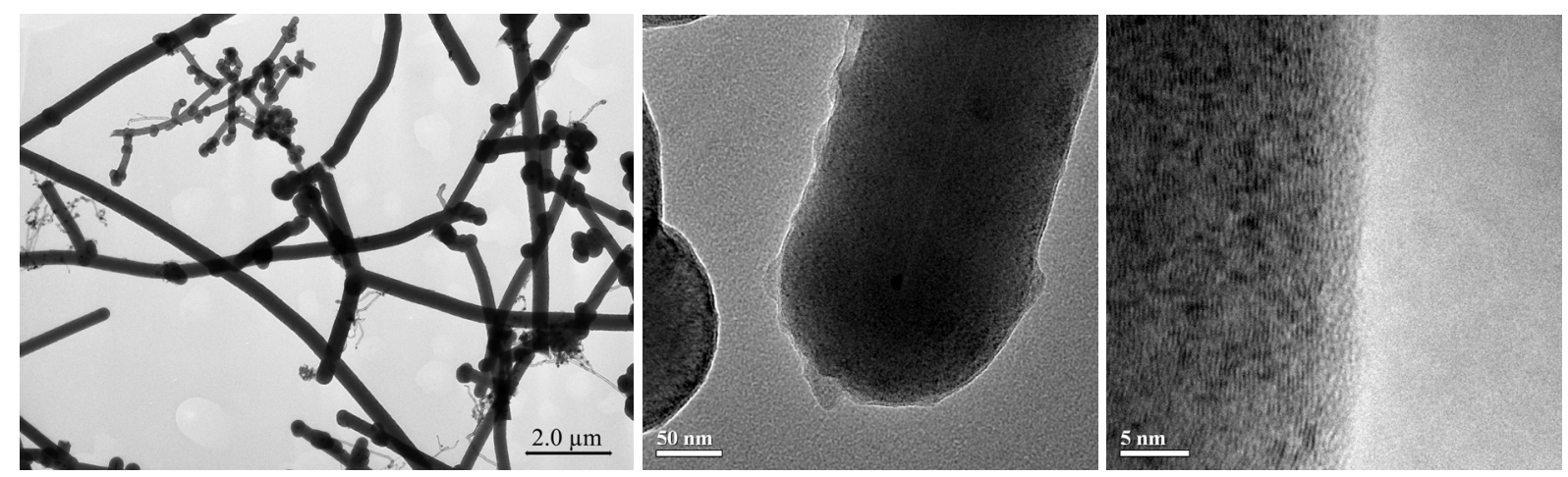

Fig. 2. TEM micrographs of sample 1 synthesized at $800^{\circ} \mathrm{C}$. a) general view; b) thick tube grown on small Fe particle; c) HRTEM showing the structure of thick tube wall. 
At $950^{\circ} \mathrm{C}$ and at the iron content of 2 at.\%, SEM micrographs (fig. 3) illustrate that we clearly observe the existence of tubes which are much thicker, longer and quite well formed for the lower Ar flow rate (1200 as opposed to $6000 \mathrm{ml} / \mathrm{h}$ ). At the higher flow rate, the tubes have a $d_{\text {ext }}$ value from 20 to $80 \mathrm{~nm}$ whereas the lower flow rate produces tubes with $d_{\text {ext }}$ varying from 200 to $300 \mathrm{~nm}$. Many spherical nanostructures are visible on the right-hand micrograph.
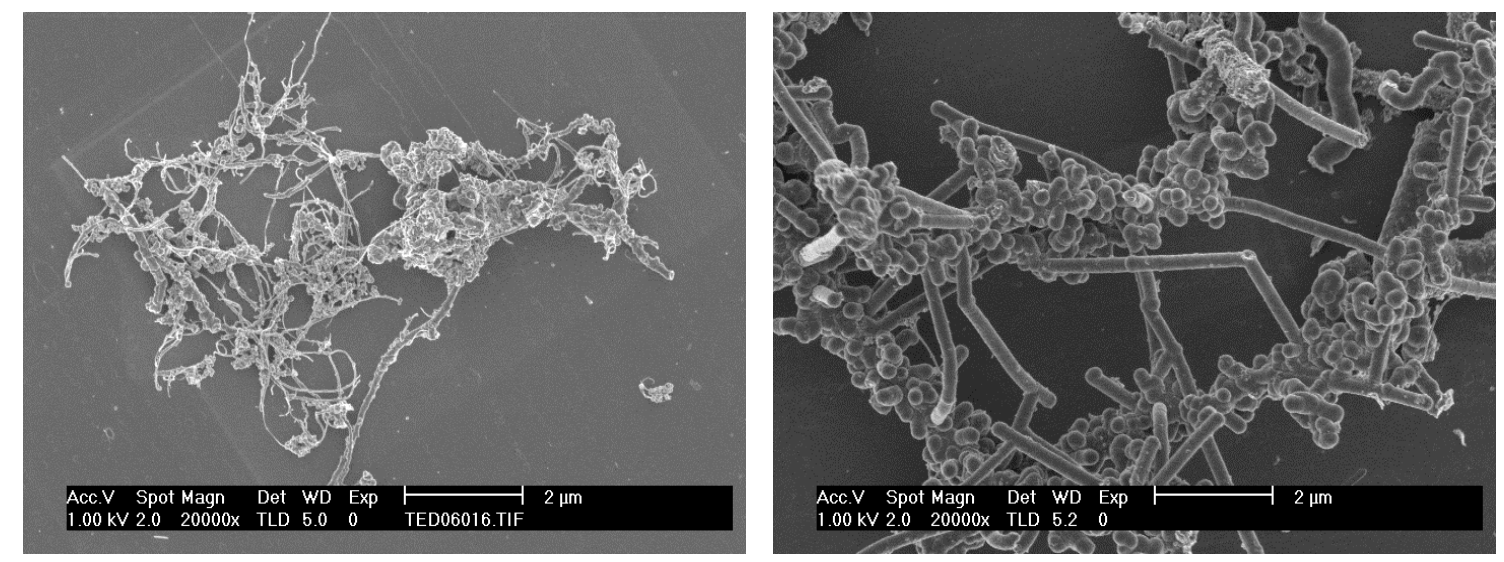

Fig. 3. SEM micrographs representative of samples synthesized at $950^{\circ} \mathrm{C}$ with an iron content of 2 at.\% and at an argon flow rate of 6000 (left, sample 3) and $1200 \mathrm{ml} / \mathrm{h}$ (right, sample 4).

Figure 4a illustrates that at the same synthesis temperature as used for the samples of figure 3, an increased iron content of $5 \mathrm{at} \%$ at an Ar flow rate of $6000 \mathrm{ml} / \mathrm{h}$ leads to a very significant increase in the tube thickness, much greater than that provoked by the lower $\mathrm{Ar}$ flow rate (fig. 3, right). The tubes in this case now have $d_{\text {ext }}$ values ranging from 400 to 800 $\mathrm{nm}$ and they are notably longer than under the previous conditions, with a length that can attain several tens of microns. We believe that this may be attributed to formation of larger catalyst particles due to aggregation of iron upon the ferrocene decomposition. Once again, many more or less spherical entities appear on the tube surfaces.
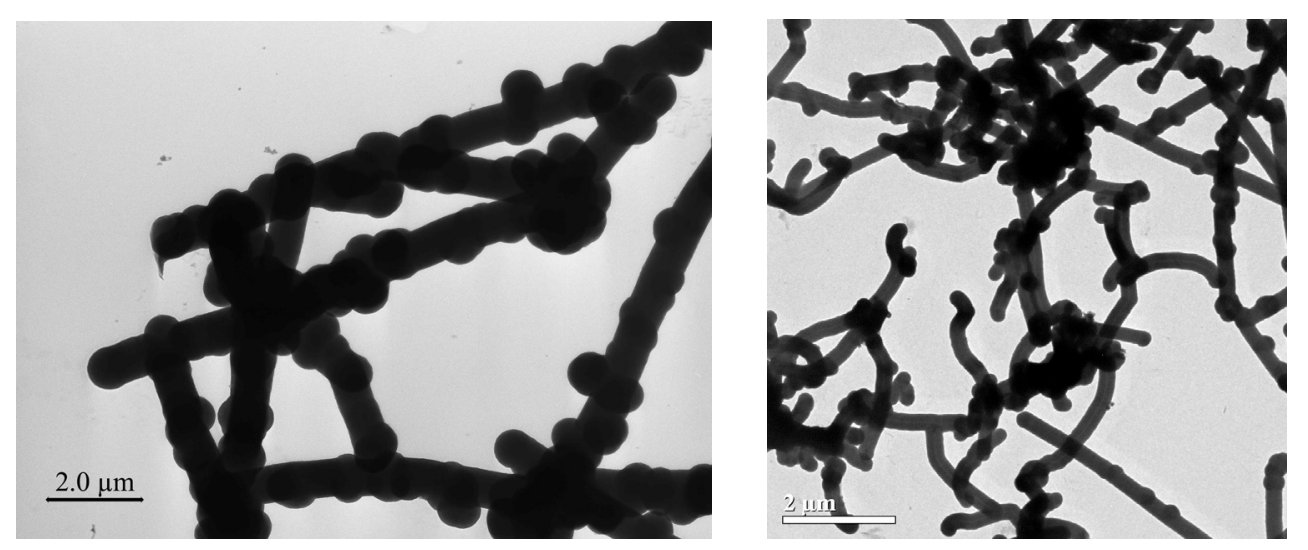

Fig. 4. a) Sample 2, synthesized at $950^{\circ} \mathrm{C}$, with an argon flow rate of $6000 \mathrm{ml} / \mathrm{h}$ and an $\mathrm{Fe}$ content of 5 at.\%; b) Sample 1, synthesis at $800^{\circ} \mathrm{C}$, an Ar flow rate of $6000 \mathrm{ml} / \mathrm{h}$ and an Fe content of 5 at.\%. 
Figure $4 \mathrm{~b}$ allows comparing the thickness of the tubes obtained at $800^{\circ} \mathrm{C}$ with that at $950^{\circ} \mathrm{C}$. Sample 1 was synthesized under the same argon flow rate and iron content as that of sample 2. Increasing the temperature from $800^{\circ} \mathrm{C}$ to $950^{\circ} \mathrm{C}$ enlarges the tube diameter more than twice due to the greater decomposition of benzene at the higher temperature.

From an overall point of view, upon decomposition of benzene and ferrocene at a reduced pressure, multiwalled carbon nanotubes appear with diameters from several tens to several hundreds of nanometers, often in the range $d_{\text {ext }}=200-300 \mathrm{~nm}$. Tubes up to $300-400 \mathrm{~nm}$ have well-organized structures with long straight sections and continuous inner channels. Tubes even twice as large as these can be observed under certain conditions, but their thickness makes it difficult to comment on the inner channel characteristics. The ratio of outer tube diameter to channel diameter $\left(\mathrm{d}_{\text {ext }} / \mathrm{d}_{\text {int }}\right)$ can be as large as 200 . Most of the conditions employed lead to the appearance of tubes which are decorated by spherical objects on the outer walls.

Analysis of our full TEM and SEM study allows bringing out a number of interesting results concerning the importance of the synthesis temperature, the Ar flow rate and the iron catalyst content.

Comparison of sample 2 (fig. 4a) with samples 1 (fig. 2 and fig. $4 \mathrm{~b}$ ) and with sample 3 (fig. 3, left) shows that tubes of significantly greater diameter result from increasing either the temperature or the catalyst content when the two other parameters are kept constant. Comparison of the results relative to samples 3 and 4 (figure 3), illustrates, on the other hand, that a lower argon flow rate leads to thicker tubes. We conclude from this that the flow rate must be sufficiently low that the hydrocarbon and the precatalysts have time to completely decompose but this decomposition time depends on the iron content and the reactor temperature. For the conditions employed in this study, a sufficiently low argon flow rate, higher iron content and a higher temperature lead to producing tubes of the greatest thickness.

The use of $\mathrm{CS}_{2}$ as an additive allows us to synthesize many junctioned multiwalled nanotubes. This work presented here is the first step of a study on the formation of junctioned nanostructures that we will present in a future paper [5]. The conditions under which carbon nanospheres are formed was recently dealt with in some detail by Mioa et al. [6] and we will also analyze this in work to come.

The authors of this research express their gratitude to the French Ministry of Foreign Affairs and to the Lorraine Regional Council for financial support of this research through the ARCUS project.

\section{References:}

1. M.S. Dresselhaus, G. Dresselhaus, P. C. Eklund, Science of Fullerens and Carbon Nanotubes, Academic Press (1996).

2. M.S. Dresselhaus, G. Dresselhaus, Ph. Avouris, eds., Carbon Nanotubes: Synthesis, Structure, Properties, and Applications. Topics in Applied Physics, 80, Springer Berlin (2001).

3. M. Meyyappan, ed., Carbon Nanotubes: Science and Applications. CRC Press (2003).

4. A. Loiseau, P. Launois, P. Petit, S. Roche and J.-P. Salvetat, eds., Understanding Carbon Nanotubes. Springer (2006).

5. S. Yu Tsareva, X. Devaux, E. McRae et al., to be published.

6. J.-Y. Miao et al., Carbon 42, 813 (2004). 